\title{
The Effect of Input Parameter Variation on the Accuracy of a Vanadium Redox Flow Battery Simulation Model
}

\author{
Christina Zugschwert ${ }^{1,2, * \mathbb{D}}$, Jan Dundálek ${ }^{3,4}$, Stephan Leyer ${ }^{2}$, Jean-Régis Hadji-Minaglou ${ }^{2}$ (D) Juraj Kosek ${ }^{3,4}$ (D) \\ and Karl-Heinz Pettinger 1
}

1 Technology Centre Energy, University of Applied Sciences Landshut, Wiesenweg 1, 94099 Ruhstorf an der Rott, Germany; Karl-Heinz.Pettinger@haw-landshut.de

2 Faculty of Science, Technology and Communication, University of Luxembourg, 6, rue Richard Coudenhove-Kalergi, L-1359 Luxembourg, Luxembourg; stephan.leyer@uni.lu (S.L.); jean-regis.minaglou@uni.lu (J.-R.H.-M.)

3 Department of Chemical Engineering, University of Chemistry and Technology, Technická 5, Dejvice, 16628 Praha 6, Czech Republic; Jan.Dundalek@vscht.cz (J.D.); Juraj.Kosek@vscht.cz (J.K.)

4 New Technologies-Research Centre, University of West Bohemia, Univerzitní 8, 30614 Plzeň, Czech Republic

* Correspondence: Christina.Zugschwert@haw-landshut.de

Citation: Zugschwert, C.; Dundálek, J.; Leyer, S.; Hadji-Minaglou, J.-R.; Kosek, J.; Pettinger, K.-H. The Effect of Input Parameter Variation on the Accuracy of a Vanadium Redox Flow Battery Simulation Model. Batteries 2021, 7, 7. https://doi.org/10.3390/ batteries7010007

Received: 28 October 2020

Accepted: 14 December 2020

Published: 19 January 2021

Publisher's Note: MDPI stays neutra with regard to jurisdictional claims in published maps and institutional affiliations.

Copyright: (c) 2021 by the authors. Licensee MDPI, Basel, Switzerland. This article is an open access article distributed under the terms and conditions of the Creative Commons Attribution (CC BY) license (https:// creativecommons.org/licenses/by/ $4.0 /)$.

\begin{abstract}
Accurately predicting battery behavior, while using low input data, is highly desirable in embedded simulation architectures like grid or integrated energy system analysis. Currently, the available vanadium redox flow battery (VRFB) models achieve highly accurate predictions of electrochemical behavior or control algorithms, while the optimization of the required input data scope is neglected. In this study, a parametrization tool for a DC grey box simulation model is developed using measurements with a $10 \mathrm{~kW} / 100 \mathrm{kWh}$ VRFB. An objective function is applied to optimize the required input data scope while analyzing simulation accuracy. The model is based on a differential-algebraic system, and an optimization process allows model parameter estimation and verification while reducing the input data scope. Current losses, theoretical storage capacity, open circuit voltage, and ohmic cell resistance are used as fitting parameters. Internal electrochemical phenomena are represented by a self-discharge current while material related losses are represented by a changing ohmic resistance. Upon reducing input data the deviation between the model and measurements shows an insignificant increase of $2 \%$ even for a $60 \%$ input data reduction. The developed grey box model is easily adaptable to other VRFB and is highly integrable into an existing energy architecture.
\end{abstract}

Keywords: vanadium redox flow battery; redox flow battery; modeling; energy storage; grey box simulation model; parameter optimization process; integrated energy system simulations; model parametrization; applications

\section{Introduction}

Leading Europe to a more sustainable future, especially considering the energy production, the amount of renewable energy sources (RES) in the grid increased rapidly during the last decade. Compared to conventional power plants, e.g., coal, RES are often not located on central network connection points, but are widespread over rural areas. Naturally, RES lead to high fluctuations in the daily generation profile all over the grid and to grid stability problems like infringement of local voltage or power quality. The use of electric energy storage (EES) is a possible option to mitigate negative effects of the decentralized intermittent RES [1].

During the last decade, vanadium redox flow batteries (VRFB), developed and patented in 1980s by M. Skyllar-Kazacos et al. [2], have drawn attention especially for large storage applications. Since then, many research groups have been focused on improving 
VRFB materials [3-8], control algorithms [9-15] and on techno-economic analysis [16-19]. Compared to other electrochemical EES, VRFB show technical and ecological benefits. Due to the principle of storing the energy in tanks, the ratio of power and energy can be scaled up easily and independently. Furthermore, VRFB systems show high energy efficiency, low costs for large capacities, and long lifetimes $[2,16,20]$.

Positive effects of distributed EES on the grid stabilization, as well as high life-time, high overall efficiency, and short reaction times strongly depend on their control algorithms $[21,22]$ and their strategic placement in the grid [23,24]. The computational analysis of single storage applications, as well as whole grid segments are necessary to evaluate the effect of EES for different time scales, different grid areas or inhomogeneous consumer and producer distributions, and facilitate decision criteria for storage placement. Simple battery models, thereby balancing accuracy, complexity and input data scope are essential for implementing the characteristics of EES and control algorithms within embedded energy architectures. Depending on the used modeling approach, different scopes of input data are used for the parameter estimation and model validation. Generally, EES models can be categorized based on their field of research (component and system research), on their modeling approach (white, grey and black box models [25]) and their input data. Battery models should map real behavior, while using low amounts of input data and need to be capable of being integrated into existing energy architecture like grid networks.

Some studies focusing on simple grey box VRFB models fitted with measured data have been already presented. For behavior approximation, these models use equivalent circuits [26-28], simplified equations or black box modeling approaches [29]. Often, separated submodeling steps, e.g., for battery, inverter, controller or auxiliary consumption are considered.

A dynamic model of a VRFB was developed by Baccino et al. using measurements from a $15 \mathrm{~kW} / 320 \mathrm{kWh}$ VRFB and an equivalent circuit approach [26]. A more detailed equivalent circuit model was proposed by Bhattacharjee et al. simulating the interface of VRFB with renewable energy sources while designing a suitable battery management system. The model gives a precise analysis of VRFB systems, but also necessitates for a high amount of input data like membrane thickness. [28] D'Agostino et al. introduced a semi-empirical model developed with a $6 \mathrm{~kW} / 20 \mathrm{kWh}$ VRFB. He used a simplified modeling approach to reduce computational time. Comparable to this paper, $\mathrm{D}^{\prime}$ Agostino et al. considered integrated energy system analysis with EES as the purpose of use of their model while a reduction of the input data scope was neglected [27]. An electrical circuit model developed by Chahwan et al. evaluates the transient behavior of a VRFB in connection with a wind energy system. Comparable to the aforementioned study from D'Agostino et al. the authors focused on a trade-off between simulation time and modeling complexity and also revealed several types of battery losses [30]. Additionally, Qiu et al. simplified an existing equivalent circuit model of a VRFB to develop a new control strategy for VRFB, while neglecting input data scope [31]. Turker et al. aimed at a wide utilization of their model for different research fields, as well as its up-scaling for megawatt batteries. Therefore, they developed a power dependent efficiency matrix to parameterize a black box simulation model of a $10 \mathrm{~kW} / 100 \mathrm{kWh}$ VRFB, without aiming for universal parametrization [29].

Several modeling approaches for VRFB, following different research objectives, have been published so far and numerous research areas necessitate simple models of EES, which can easily be adapted for various systems architectures. To the best of our knowledge so far no research has been carried out to understand the required input data scope to balance the complexity and the accuracy for model parametrization of grey box VRFB models. Currently available VRFB models are intended to achieve highly accurate predictions, and to serve for detailed analysis of electrochemical behavior or control algorithms, while the optimization of the required input data scope is often neglected.

The aim of this study is to develop a simple, grey box battery model and parametrize this model with experiments from a $10 \mathrm{~kW} / 100 \mathrm{kWh}$ VRFB. The DC battery behavior and internal processes are described with deterministic equations and physico-chemical 
knowledge of VRFB, while inverters, pumps, ventilation and system electronics are excluded from the model. The focus of the study is to minimize the amount of measurements (input data scope) necessary for the parametrization. During model development, we can distinguish between parameter estimation and model validation to some experimental data not employed for parameter fitting. Therefore, the validation step typically tests the model prediction capabilities. A sufficient agreement between experiments and model, a simple adaptability and integrability to further computational analysis is pursued. The outcome meets the reality of simulating the interfaces between different energy system architectures by applying a minimized input data scope.

\section{Results and Discussion}

Performing the optimization process described in Section 3 for all evaluation cases, fitting parameters, least square sum (LSS), as well as weighted least square sum (WLSS) are stored for different input data scopes. The effect of a reduced data scope (index $p$ ) as an input for the optimization process is elaborated.

Table 1 shows a summary of all evaluation cases used within this study. Ten different variations of the vector $P_{a p l}$ are defined to determine the effect of different input data scopes on the parameter estimation and thus on the accuracy of the model. Evaluation cases are selected to represent different performance ranges of the battery e.g., maximum and minimum values of $P_{a p l}$ in Case $2 \mathrm{~A}$ and additional medium value in Case 3A. Additionally, Case 2B and Case 3B exclude upper and lower boundaries in $P_{a p l}$ as especially low powers show different pumping behavior and stack performance including lower efficiencies. While during Cases $2 \mathrm{~A}$ and $3 \mathrm{~A}$ the battery behavior is interpolated between end point values of the power range, Case $2 \mathrm{~B}$ and Case $3 \mathrm{~B}$ show an extrapolation of the behavior, as only middle values are used. Case 4 uses all power values separately, indicating power specific performance issues.

Table 1. Evaluation cases for the VRFB model.

\begin{tabular}{cccc}
\hline Evaluation Case & $\boldsymbol{P}_{\boldsymbol{a p l}} \mathbf{( k W )}$ & Index $\boldsymbol{p}$ in $\boldsymbol{P}_{\boldsymbol{a p l}}$ & Index $\boldsymbol{n}^{\mathbf{1}}$ \\
\hline Case 1 & $1,2.5,5,7.5,10$ & $p 1=[1 ; 2 ; 3 ; 4 ; 5]$ & 10 \\
Case 2A & 1,10 & $p 2=[1 ; 5]$ & 4 \\
Case 2B & $2.5,7.5$ & $p 3=[2 ; 4]$ & 4 \\
Case 3A & $1,5,10$ & $p 4=[1 ; 3 ; 5]$ & 6 \\
Case 3B & $2.5,5,7.5$ & $p 5=[2 ; 3 ; 4]$ & 6 \\
Case 4A & 1 & $p 6=[1]$ & 2 \\
Case 4B & 2.5 & $p 7=[2]$ & 2 \\
Case 4C & 5 & $p 8=[3]$ & 2 \\
Case 4D & 7.5 & $p 9=[4]$ & 2 \\
Case 4E & 10 & $p 10=[5]$ & 2 \\
\hline
\end{tabular}

${ }^{1}$ Amount of half-cycles used for the parametrization.

\subsection{Model Validation for Power Specific Parametrization}

The Power Specific Parametrization (PSP) implies a power separated model parametrization, revealing power related performance issues of the VRFB. Fitting parameters and the corresponding WLSS are optimized for each power separately instead of optimizing them along the overall power range. Except for Case 4, evaluation cases always map a mixed behavior of the battery as more than one cycle is used for the parametrization. Table 2 provides the optimal values of all fitted parameters as a lookup table. All fitting parameters show only slight changes for different $P_{\text {apl }}$. $U_{0}{ }^{\prime}$ reduces from $1 \mathrm{~kW}$ to $5 \mathrm{~kW}$ by $1 \%$ and stays nearly constant for all other powers. $I_{\text {Loss }}$ fluctuates slightly with a median value of $7.17 \mathrm{~A}$ at 7 at $5 \mathrm{~kW} . R_{i}$ shows an increase of $16 \%$ between $1 \mathrm{~kW}$ and $2.5 \mathrm{~kW}$ and remains nearly constant for Case $4 \mathrm{D}$ and $4 \mathrm{E}$. The parameter $C_{\text {Stor }}$ varied for $P_{\text {apl }}$ in a range between $2286 \mathrm{Ah}$ and $2409 \mathrm{Ah}$. 
Table 2. Optimal model parameters for power specific parametrization.

\begin{tabular}{cccccc}
\hline Evaluation Case & Fitting Parameters & $\boldsymbol{R}_{\boldsymbol{i}} /(\mathbf{m} \Omega)$ & $\boldsymbol{U}_{\mathbf{0}}{ }^{\prime} /(\mathbf{V})$ & $\boldsymbol{I}_{\text {Loss }} /(\mathbf{A})$ & $\boldsymbol{C}_{\text {Stor }} /(\mathrm{Ah})$ \\
\hline Case 4A & $1 \mathrm{~kW}$ & 0.5602 & 1.3846 & 7.01 & 2321 \\
Case 4B & $2.5 \mathrm{~kW}$ & 0.6489 & 1.3822 & 8.62 & 2286 \\
Case 4C & $5 \mathrm{~kW}$ & 0.6736 & 1.3774 & 6.06 & 2409 \\
Case 4D & $7.5 \mathrm{~kW}$ & 0.6316 & 1.3730 & 7.17 & 2363 \\
Case 4E & $10 \mathrm{~kW}$ & 0.6337 & 1.3749 & 8.30 & 2402 \\
\hline
\end{tabular}

Table 3 shows the results for the PSP per evaluation case and performed cycle. The deviation error WLSS is normalized to the lowest error for each power values in $P_{a p l}$, as described in Section 3.2.3. WLSS is calculated in relation to initial cases marked with a star in Table 3. For all values of $P_{a p l}$ despite the $10 \mathrm{~kW}$ cycle the lowest WLSS is reached at Case 4. Contrary to all other cases, the lowest WLSS of $10 \mathrm{~kW}$ cycle occurs at Case 1 and even Case 3A shows a lower result than Case 4 . In general, results for $1 \mathrm{~kW}, 2.5 \mathrm{~kW}$, and $5 \mathrm{~kW}$ cycle show a broad dispersion of WLSS for different evaluation cases while WLSS for $10 \mathrm{~kW}$ and $7.5 \mathrm{~kW}$ remain nearly constant. The continuously low WLSS of the $7.5 \mathrm{~kW}$ and $10 \mathrm{~kW}$ cycle indicates a stable performance and fewer non-linear effects which can be reproduced sufficiently also by other evaluation cases. As soon as one of the two cycles $(7.5 \mathrm{~kW}, 10 \mathrm{~kW})$ is included in the parameterization e.g., Case $2 \mathrm{~A}$ or Case $3 \mathrm{~A}$, the behavior of both power values can be mapped accurately. While $7.5 \mathrm{~kW}$ shows almost constant and low WLSS for all cases, $2.5 \mathrm{~kW}$ presents high deviation errors. If the $2.5 \mathrm{~kW}$ cycle is not included in the parameterization, for example in Case 2A and Case 3A the WLSS increases significantly up to $294 \%$ and $283 \%$, respectively. Similarities can be confirmed for the $1 \mathrm{~kW}$ cycle with an increase of the WLSS of $487 \%$ and $136 \%$ in Case 2B and 3B. Thus both the $1 \mathrm{~kW}$ and $2.5 \mathrm{~kW}$, show a specific behavior which cannot be represented sufficiently by other cycles. While Case 2A and $3 \mathrm{~A}$ interpolate the battery behavior within the complete power range, both Cases $2 \mathrm{~B}$ and $3 \mathrm{~B}$ only interpolate the battery behavior between $2.5 \mathrm{~kW}$ and $7.5 \mathrm{~kW}$. Therefore, the model needs to extrapolate power values outside the range, leading to higher deviation error.

Table 3. Deviation of WLSS for power specific parametrization.

\begin{tabular}{ccccccc}
\hline \multirow{2}{*}{$\boldsymbol{P}_{\text {apl }}$} & \multicolumn{7}{c}{ WLSS/(\%) } \\
\cline { 2 - 7 } & Case 1 & Case 2A & Case 2B & Case 3A & Case 3B & Case 4 \\
\hline $1 \mathrm{~kW}$ & 7.2 & 10.6 & 487.1 & 13.8 & 136.3 & $*$ \\
$2.5 \mathrm{~kW}$ & 278.9 & 293.6 & 96.5 & 283.3 & 104.0 & $*$ \\
$5 \mathrm{~kW}$ & 32.6 & 30.4 & 102.5 & 28.6 & 85.0 & $*$ \\
$7.5 \mathrm{~kW}$ & 2.9 & 2.9 & 2.0. & 3.9 & 0.5 & $*$ \\
$10 \mathrm{~kW}$ & $*$ & 15.7 & 12.8 & 0.7 & 13.1 & 11.5 \\
\hline
\end{tabular}

*: Initial case for WLSS calculation; WLSS equals $0 \%$.

\subsection{Model Validation for Universally Valid Parametrization}

Universally valid parametrization (UVP) presents a new method yielding for sufficient model accuracy while reducing the input data scope for the parametrization. The programming effort for integrating the battery model into superimposed simulations such as network simulations is reduced, as one set of fitting parameters describes the battery performance sufficiently in all power ranges. Except for Case 4, evaluation cases always map a mixed behavior of the battery, as more than one cycle is used for the parametrization. Case 4 is subscripted with $1 \mathrm{~kW}$ to $10 \mathrm{~kW}$, as only one cycling data set is used for the parametrization. Contrary to the lookup table (PSP) discussed above, Table 4 provides optimal values of all fitted parameters per evaluation case. Evaluation cases show different input data scopes related to the number of cycles used for the parametrization. 
Table 4. Optimal model parameters for universally valid parametrization.

\begin{tabular}{ccccc}
\hline Evaluation Cases & $\boldsymbol{R}_{\boldsymbol{i}} /(\mathbf{m} \boldsymbol{\Omega})$ & $\boldsymbol{U}_{\mathbf{0}}{ }^{\prime} /(\mathbf{V})$ & $\boldsymbol{I}_{\text {Loss }} /(\mathbf{A})$ & $\boldsymbol{C}_{\text {Stor }} /(\mathbf{A h})$ \\
\hline Case 1 & 0.6387 & 1.3755 & 6.94 & 2386 \\
Case 2A & 0.6425 & 1.3767 & 6.82 & 2382 \\
Case 2B & 0.6285 & 1.3755 & 8.16 & 2367 \\
Case 3A & 0.6426 & 1.3766 & 6.93 & 2387 \\
Case 3B & 0,6399 & 1.3762 & 7.89 & 2367 \\
Case $41 \mathrm{~kW}$ & 0.5602 & 1.3846 & 7.01 & 2321 \\
Case $4.5 \mathrm{~kW}$ & 0.6489 & 1.3822 & 8.62 & 2286 \\
Case $45 \mathrm{~kW}$ & 0.6736 & 1.3774 & 6.06 & 2409 \\
Case $47.5 \mathrm{~kW}$ & 0.6316 & 1.3730 & 7.17 & 2363 \\
Case $410 \mathrm{~kW}$ & 0.6337 & 1.3749 & 8.30 & 2402 \\
\hline
\end{tabular}

Parameters in Table 4 are used to simulate the complete battery behavior while the effect of input data scope on the model accuracy is investigated. While, $U_{0}{ }^{\prime}$ changes slightly between different evaluation cases, $R_{i}$ varies in a range between $0.5602 \mathrm{~m} \Omega$ in Case $4_{1} \mathrm{~kW}$ and $0.6734 \mathrm{~m} \Omega$ in Case $4_{5} \mathrm{~kW}$. Same can be found for $I_{\text {Loss }}$, varying in a range between $8.62 \mathrm{~A}$ in Case $4_{2.5} \mathrm{~kW}$ and $6.06 \mathrm{~A}$ in Case $4_{5} \mathrm{~kW}$. The parameter $C_{\text {Stor }}$ changes slightly from Case 1 to Case 3B. Significant changes can be found in all Case 4 evaluations. While PSP optimize fitting parameters per power value, the UVP is used to optimize parameters for the complete power range and to evaluate possibilities for data input reduction. Thus, UVP method aims to find an input data scope mapping the overall battery behavior best.

Table 5 shows the WLSS of all evaluation cases in the UVP. The battery is charged and discharged in the complete power range $(1 \mathrm{~kW}$ to $10 \mathrm{~kW})$ with the respective parameters from Table 4 per evaluation case. The maximum data scope (Case 1) reveals the lowest WLSS and is set as initial case. Again, the WLSS of following cases is always calculated in relation to the initial case in percent. By reducing the data scope from Case 1 ( 5 cycles), Case 2 ( 2 cycle), Case 3 ( 3 cycles), and Case 4 ( 1 cycle) the accuracy of the simulation model as well as the time-requirement for appropriate data acquisition is reduced. Case 2A uses only maximum and minimum power, the extended Case $3 \mathrm{~A}$ uses also the medium power value. In Cases $3 \mathrm{~B}$ both the maximum and minimum power $(1 \mathrm{~kW}$ and $10 \mathrm{~kW})$ are excluded from the data scope.

Table 5. Deviation of WLSS for for universally valid parametrization for all values in $P_{a p l}$.

\begin{tabular}{ccccc}
\hline \multicolumn{5}{c}{ WLSS/(\%) } \\
\hline Case 1 & Case 2A & Case 2B & Case 3A & Case 3B \\
\hline$*$ & 1.67 & 52.76 & 6.98 & 82.58 \\
\hline Case 4A & Case 4B & Case 4C & Case 4D & Case 4E \\
\hline 129.65 & 187.58 & 100.14 & 7.90 & 120.51 \\
\hline
\end{tabular}

*: Initial case for WLSS calculation; WLSS equals $0 \%$.

WLSS in Case 2A (1 kW, $10 \mathrm{~kW})$ shows an increase of $6.98 \%$ while input data scope is decreased by $60 \%$. In comparison, Case $2 \mathrm{~B}(2.5 \mathrm{~kW}, 7.5 \mathrm{~kW})$ WLSS is increased by $80 \%$ for the same data scope reduction. The results indicate, that using the end point values of the battery's power range ( $1 \mathrm{~kW}$ and $10 \mathrm{~kW}$, in Case $2 \mathrm{~A}$ ) shows better results, as we are interpolating the battery's behavior between these boundary values. Contrary, using only middle values of the battery's power range ( $2.5 \mathrm{~kW}$ and $7.5 \mathrm{~kW}$, in Case $2 \mathrm{~B})$ leads to less accuracy, as the model needs to extrapolate outside the used power range. Similarly, behavior is found between Case 3A and 3B. While, Case 3A shows the lowest increase of the WLSS of $1.67 \%$ using minimal, medium, and maximal power values $(1 \mathrm{~kW}, 5 \mathrm{~kW}, 10 \mathrm{~kW})$, WLSS in Case 3B is increased by 53\%. Performing UVP with only one cycle measurement (Case 4) leads to a wide range of results. The worst WLSS is achieved using $P_{a p l}=2.5 \mathrm{~kW}$. The deviation error is $188 \%$ higher than the initial point. Similarly, the $P_{a p l}=1 \mathrm{~kW}$ leads to 
a high WLSS. Using medium and high power values (above $5 \mathrm{~kW}$ ), lead to better results, compared to values below $5 \mathrm{~kW}$.

While, using more experiments in Case 1 gives generally better results, a reduction of the used experiments about $40 \%$ (Case 3A) still leads to a high accuracy of the DC model. Even a reduction of the input data about $60 \%$ (Case 2A) shows sufficient results. In both cases, the input data scope and time for the data acquisition could be significantly reduced while the accuracy in relation to Case 1 is still high with WLSS of $2 \%$ and $7 \%$. Power values with high and nearly constant DC efficiency $(5 \mathrm{~kW}, 7.5 \mathrm{~kW}, 10 \mathrm{~kW})$ are able to represent the VRFB with lower WLSS than power values $(1 \mathrm{~kW}, 2.5 \mathrm{~kW})$ with low DC efficiency. By including high power values into parametrization, the overall model performance can be mapped sufficiently. Moreover, the $1 \mathrm{~kW}$ cycle should be included into the parametrization process as it shows specific behavior with drops in the voltage and State of Charge (SoC) profile.

\subsection{Accuracy Evaluation for Charging and Discharging Cycles}

Charging and discharging cycles at different power values (Figures 1-3) are performed to evaluate the accuracy of the simulation model by comparing simulation and raw data of voltage and SoC. Besides Case 1, Case 2A is used to demonstrate data scope reduction. Model Parametrization is carried out in accordance with Table 4. Despite the $1 \mathrm{~kW}$ cycle, the simulation model is able to predict the complete battery behavior accurately in both Case 1 and Case 2A. Although, model parametrization in Case 2A is performed with a reduced data scope of $60 \%$, simulation results are in good agreement with the measurements and only a WLSS of $1.67 \%$ against initial Case 1 occurred.

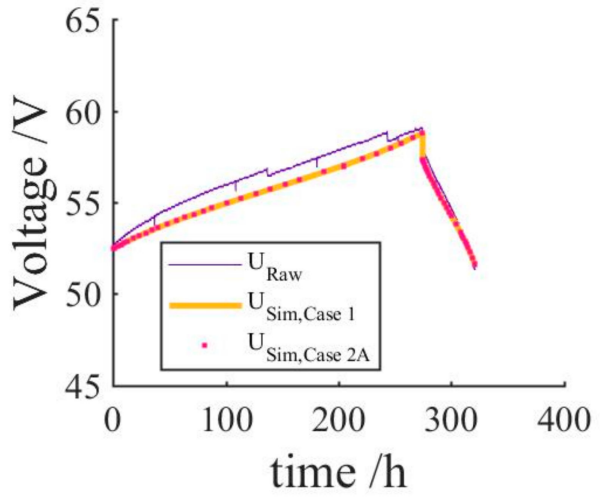

(a)

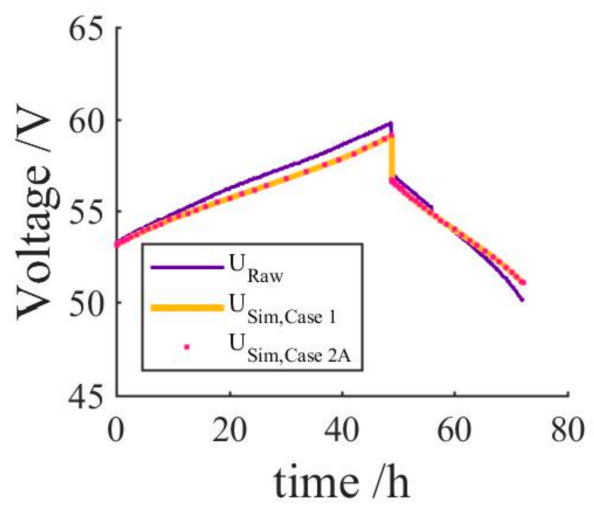

(c)

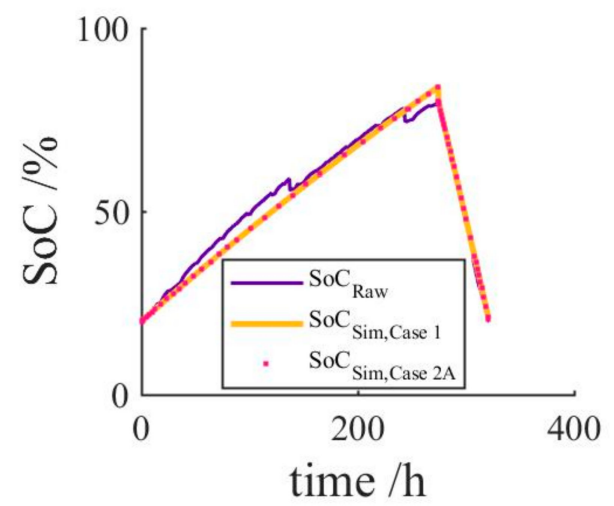

(b)

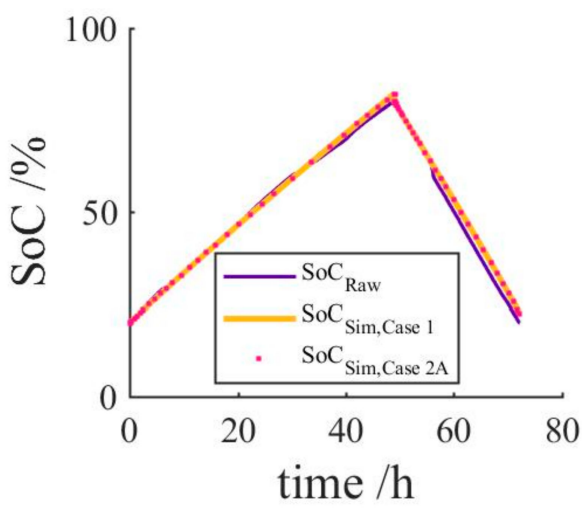

(d)

Figure 1. Comparison between simulation model and measurements using fitting Case 1 and Case 2A: (a) Voltage with $P_{a p l}$ $=1 \mathrm{~kW} ;(\mathbf{b})$ SoC with $P_{a p l}=1 \mathrm{~kW} ;(\mathbf{c})$, Voltage with $P_{a p l}=2.5 \mathrm{~kW} ;(\mathbf{d})$ SoC with $P_{a p l}=2.5 \mathrm{~kW}$. 


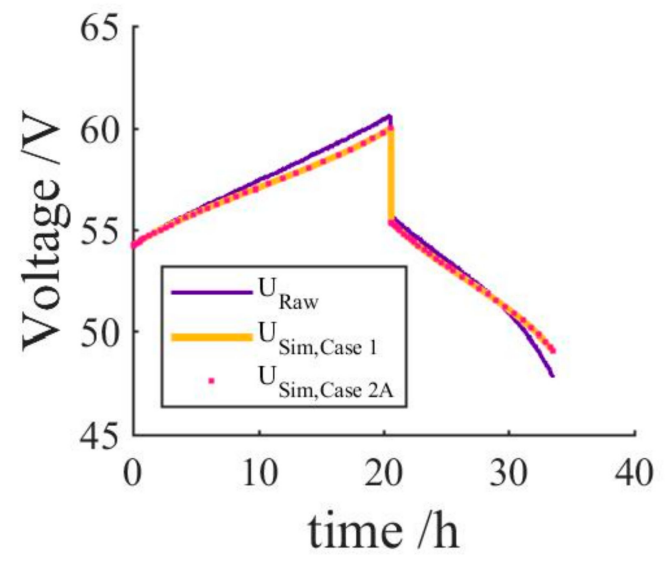

(a)

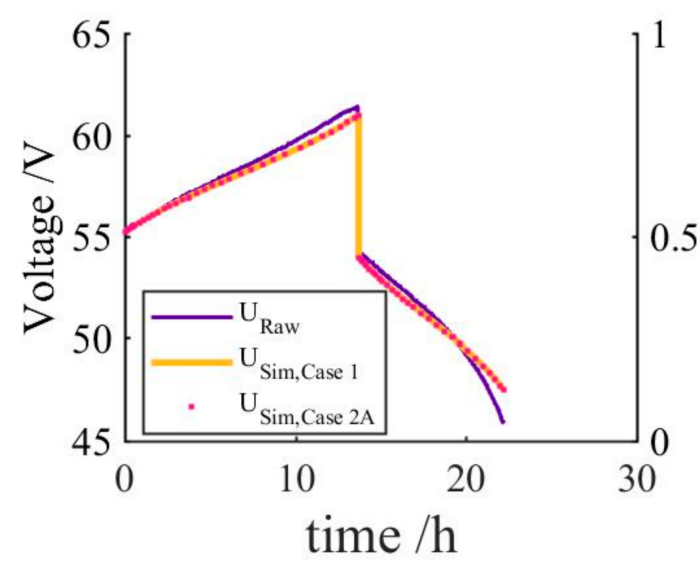

(c)

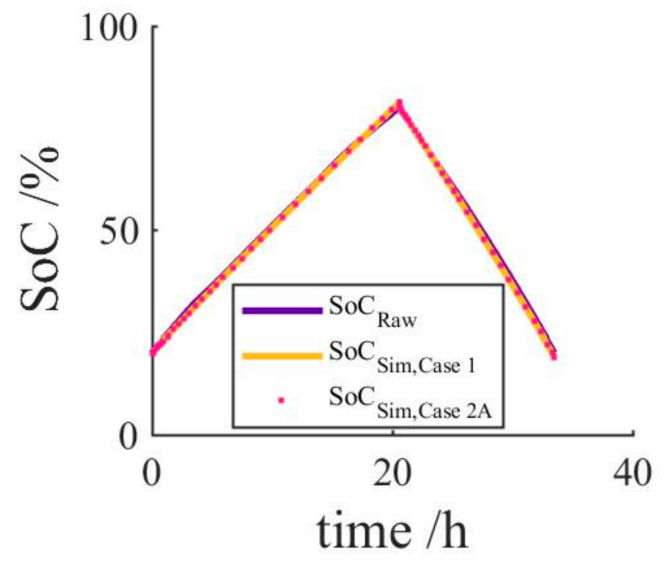

(b)

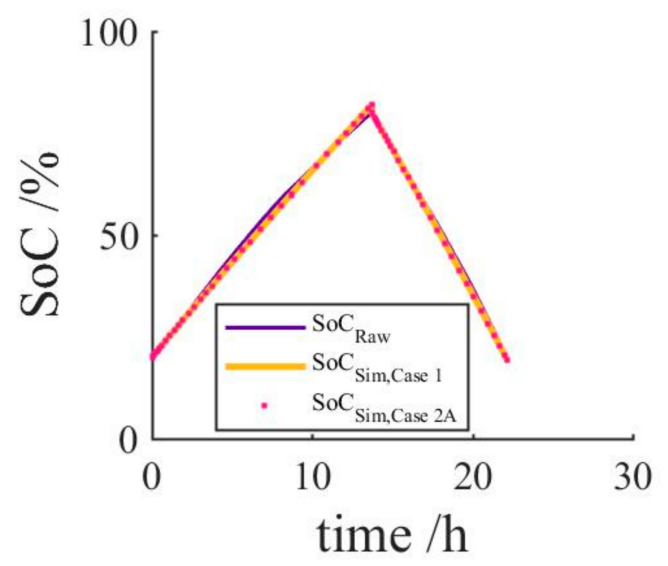

(d)

Figure 2. Comparison between simulation model and measurements using fitting Case 1 and Case 2A: (a) Voltage with $P_{\text {apl }}$ $=5 \mathrm{~kW} ;(\mathbf{b})$ SoC with $P_{a p l}=5 \mathrm{~kW} ;(\mathbf{c})$, Voltage with $P_{a p l}=7.5 \mathrm{~kW} ;(\mathbf{d})$ SoC with $P_{a p l}=7.5 \mathrm{~kW}$.

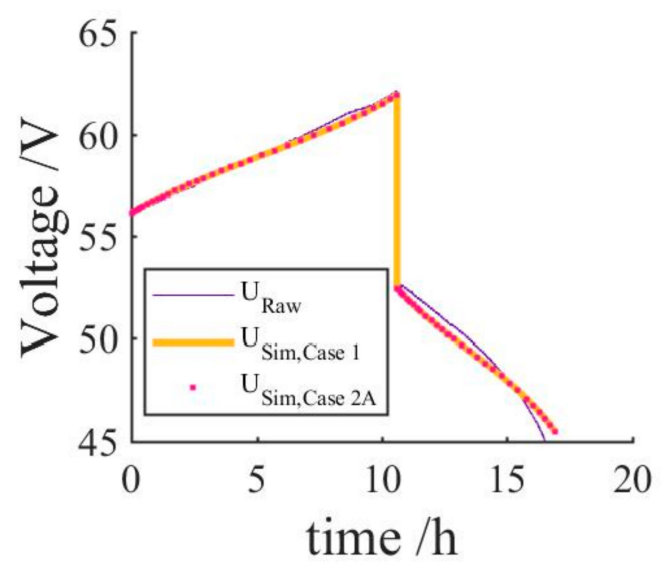

(a)

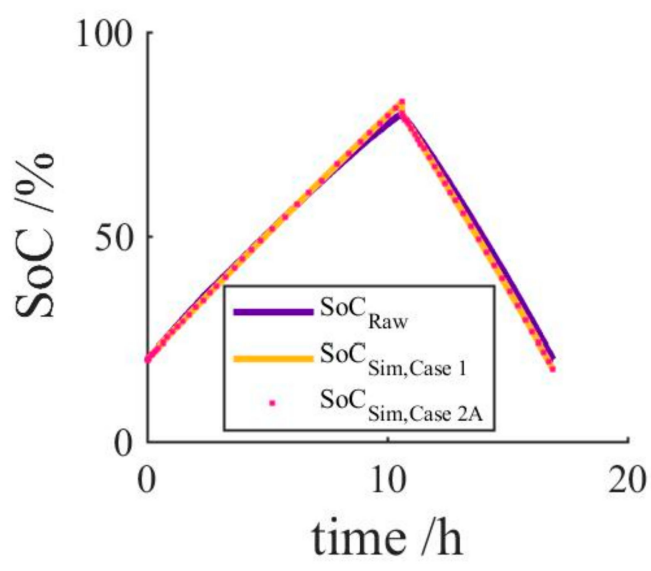

(b)

Figure 3. Comparison between simulation model and measurements using fitting Case 1 and Case 2A: (a) Voltage with $P_{a p l}=10 \mathrm{~kW} ;(\mathbf{b})$ SoC with $P_{a p l}=10 \mathrm{~kW}$.

Unpredictable drops in the voltage and SoC profile occur during the $1 \mathrm{~kW}$ charging cycle while the external charging current remains unaffected (Figure 1a). The first drop of $3 \%$ occurs after $136 \mathrm{~h}$ and last one hour before the charging process continues. The same 
effect is observed after $240 \mathrm{~h}$ of charging. The unpredictable changes in the voltage and $\mathrm{SoC}$ profile are caused by periodical rebalancing of the electrolyte, performed to reduce cross-contamination and to minimize capacity fading [32]. The rebalancing unit and VRFB stacks are connected to the same DC voltage bus, which may explain the influence of the rebalancing unit on the DC voltage and SoC of the battery. Due to the low efficiency of the battery at $1 \mathrm{~kW}$ of $17 \%$, the battery needs $270 \mathrm{~h}$ to be fully charged. As charging times of other cycles are far below $136 \mathrm{~h}$, the rebalancing unit is not active during the measurements.

The simulation model is not able to predict voltage and SoC drops due to the rebalancing system or other unpredictable events. Therefore, deviation error between measurements and simulation is higher during the $1 \mathrm{~kW}$ charging cycle (Figure 1). From the three state variables $\mathrm{SoC}$, voltage, and current, the voltage shows the highest deviation error.

Contrary to the aforementioned cycling with $1 \mathrm{~kW}$, simulation results with $2.5 \mathrm{~kW}$, $5 \mathrm{~kW}, 7.5 \mathrm{~kW}$, and $10 \mathrm{~kW}$ show good agreement with experiments. The simulation model reproduces the VRFB performance for the $2.5 \mathrm{~kW}$ (Figure 1c,d), $5 \mathrm{~kW}$ (Figure 2a,b), $7.5 \mathrm{~kW}$ (Figure 2c,d), and the $10 \mathrm{~kW}$ cycle (Figure 3) with sufficient accuracy. Discrepancies can be observed at the end of both the charging and discharging voltage profile, where non-linear electrochemical behavior takes place and the model is not able to predict the voltage profile correctly. The SoC prediction is stable in-between the power range.

Differences between predicted and real voltage are related to electrochemical processes and kinetics during cycling of VRFB. The real stack voltage of a VRFB is calculated using the theoretical potential represented by the Nernst Equation, subtracted by voltage drops also called overpotentials. Generally, overpotentials are related to the energy needed to carry out chemical redox-reactions. The overpotentials are grouped in activation losses, related to charge transfer process and concentration losses, based on different concentrations between electrode surface and vanadium-solution. Moreover, ohmic losses arise due to actual electrical cell resistance and ionic transport in the electrolyte, while ionic losses are caused by gradual ionic flow leading to vanadium ion and water permeation through membrane [33].

By comparing both theoretical and simulated voltage profile, differences can be qualitatively observed at the beginning of charging and ending of discharging cycle. The predicted voltage $\left(U_{\mathrm{Sim}}\right)$ shows an almost linear behavior during the half-cycles based on a linear voltage drop caused by the ohmic cell resistance. The real voltage $\left(U_{\text {Raw }}\right)$ shows a non-linear behavior due to the aforementioned overpotentials, which occur at different points in the charging or discharging cycle. Comparing the discharging cycles, it can be seen that the cell performance is limited, due to the mass-transfer phenomena. During the charging cycle, the kinetics of the chemical reaction limit the charge transfer rate.

The simple battery model describes the internal electrochemical phenomena of the VRFB using a linear approximation. Due to this approximation, the parametrization of the presented battery model is done with a reduced data scope while a sufficient accuracy can still be achieved. The presented model can easily be used with different input data-sets (experiments). Measurements performed to parametrize the model are simple power measurements, which can be realized with any battery inverter. The presented battery model can be integrated into simulation architectures of any energy system simulation by using DC power and State of Charge (SoC) of the battery. The main objectives of reduced input data scope, sufficient accuracy, adaptability, and integrability are fulfilled with the presented study.

\section{Materials and Methods}

\subsection{Experimental Set-Up}

For this study, a VRFB from Cellstrom GmbH with a nominal power of $10 \mathrm{~kW}$ and a nominal energy storage capacity of $100 \mathrm{kWh}$ is used. The technical characteristics taken from the data sheet state a reaction time of around $60 \mathrm{~ms}$ or less, an overall DC efficiency up to $80 \%$ and self-discharge of $150 \mathrm{~W}$. Moreover, an active cooling respectively heating system maintains the temperature inside the container in a safe operation range. Three 
independent hydraulic circuits enable an energy efficient pump control. The stacks are connected in parallel to a DC-bus, which is connected to three reversible DC/AC inverters coupled onto the utility grid. The auxiliary services of the battery are powered by a $24 \mathrm{~V}$ power supply connected to the DC-bus of the battery. Auxiliary power consumption is caused by the pumps, the control power system and the ventilation. The battery container is separated into two sides with five battery stacks each. Beneath each container side, a tank contains the vanadium electrolyte [34].

Within this study, complete charging and discharging cycles at different $\mathrm{AC}$ power values $P_{a p l}(1 \mathrm{~kW}, 2.5 \mathrm{~kW}, 5 \mathrm{~kW}, 7.5 \mathrm{~kW}, 10 \mathrm{~kW})$ between $20 \%$ and $80 \%$ state of charge (SoC) have been performed. There are no interruptions between charging and discharging during the measurements to avoid self-discharging of the electrolyte in the stacks. AC power, DC voltage, DC current, SoC as well as the temperature of the environment and the electrolyte, were logged every second by the energy management system (EMS) of the battery.

According to the electric circuit diagram of the battery EMS calculates the SoC based on a voltage measurement with a separate VRFB cell installed in the hydraulic cycle of the battery. A detailed explanation of the connection between the separate VRFB cell voltage (also called open circuit voltage) and the SoC calculation is given in Section 3.2. The effective AC power is measured with a network analyzer in a separate module after the inverter (on the AC side). DC losses cover the complete auxiliary power consumption of the battery while DC stack power is calculated by multiplying the charging or discharging current and the battery voltage. Figure 4a shows AC and DC efficiency in dependency on $P_{a p l}$. The efficiency is calculated using the average AC and DC power during discharging and charging process at each of the applied power values. The lowest battery AC efficiency of $17 \%$ is reached at $1 \mathrm{~kW}$, while the highest AC efficiency of $62 \%$ is reached at $5 \mathrm{~kW}$. From $5 \mathrm{~kW}$ to $10 \mathrm{~kW}$ AC efficiency decreases to $60 \%$ at $10 \mathrm{~kW}$. The DC efficiency shows a stable behavior with a decrease of $0.5 \%$ between $5 \mathrm{~kW}$ to $7.5 \mathrm{~kW}$ and a decrease of $1 \%$ from $7.5 \mathrm{~kW}$ to $10 \mathrm{~kW}$. An average DC efficiency of $77 \%$ is reached from $5 \mathrm{~kW}$ to $10 \mathrm{~kW}$. The measured DC efficiency in this study is comparable to the DC efficiency excluding the inverter losses presented in $[29,35]$. By reviewing the inverter data sheet of the studied VRFB, inverter losses at $10 \mathrm{~kW}$ are in the range of $250 \mathrm{~W}$ corresponding to $4 \%$ of the total losses.

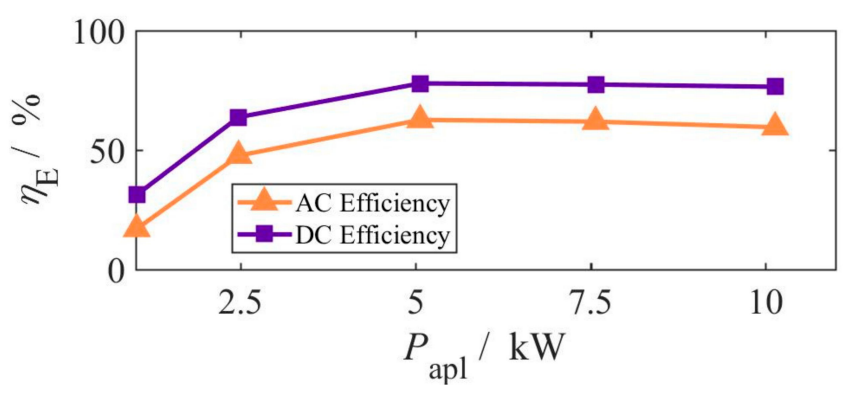

(a)

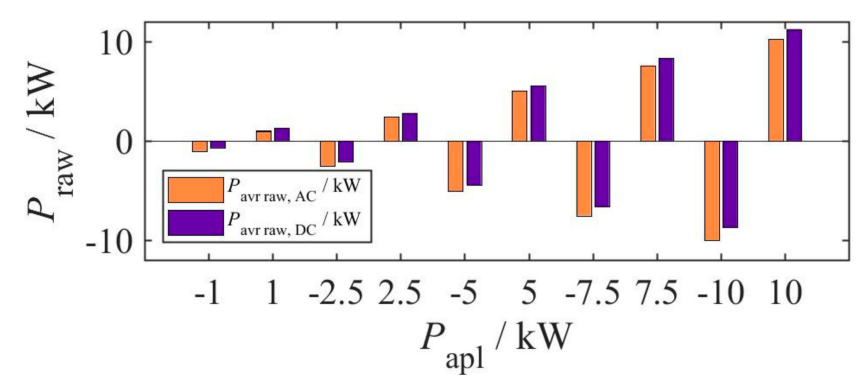

(b)

Figure 4. Battery performance evaluation: (a) Battery efficiency for charging and discharging cycles; (b) power losses between AC and DC battery power for all measurements. 
Additionally, Figure $4 \mathrm{~b}$ deals with the discrepancy between measured AC and calculated DC power for each $P_{a p l}$, separated for charging and discharging. AC power takes the complete auxiliary losses into account: Inverter and rectifier, control power system, pump, and ventilation losses. The circuit diagram of the VRFB installation shows that power control system, pumps, and ventilation system are connected directly to the DC-bus. Specification of loss shares is not possible. The highest AC to DC difference of $1.26 \mathrm{~kW}$ occured at the $10 \mathrm{~kW}$ discharging cycle. The value corresponds to a $14 \%$ loss between AC and DC power. The highest losses between AC and DC power of $48 \%$ were measured at the $1 \mathrm{~kW}$ charging cycle. Power losses in percent decreased with increasing $P_{a p l}$. The difference between losses during charge and discharge cycle decreased with increasing stack current mainly due to longer operation with lower charging/discharging power [36]. Due to different pumping strategies power losses were always higher for charging $[29,36]$.

\subsection{Method}

Figure 5 demonstrates the overall simulation process. The proposed model combines a mathematical description of a VRFB (3) with simplifications, and the optimization process (2) is based on measurements from a $10 \mathrm{~kW} / 100 \mathrm{kWh}$ system (1). The model is developed in Matlab (Version: R2017a) by using a differential-algebraic system. Steps one to three in Figure 5 show the parts of the computational analysis which are related to the battery modeling. Part one are the battery measurements, described in Section 3.1. The second part is the optimization process (also called fitting process) to estimate battery specific parameters. The last step is the battery modeling based on the measurements, the estimated parameters, and physio-chemical equations. Step four illustrates the computational environment in which the battery model can be used. The interface between the model and any kind of user environment (simulation architecture (4)) is linked by the parameters SOC and applied DC power $\left(P_{a p l}\right)$.

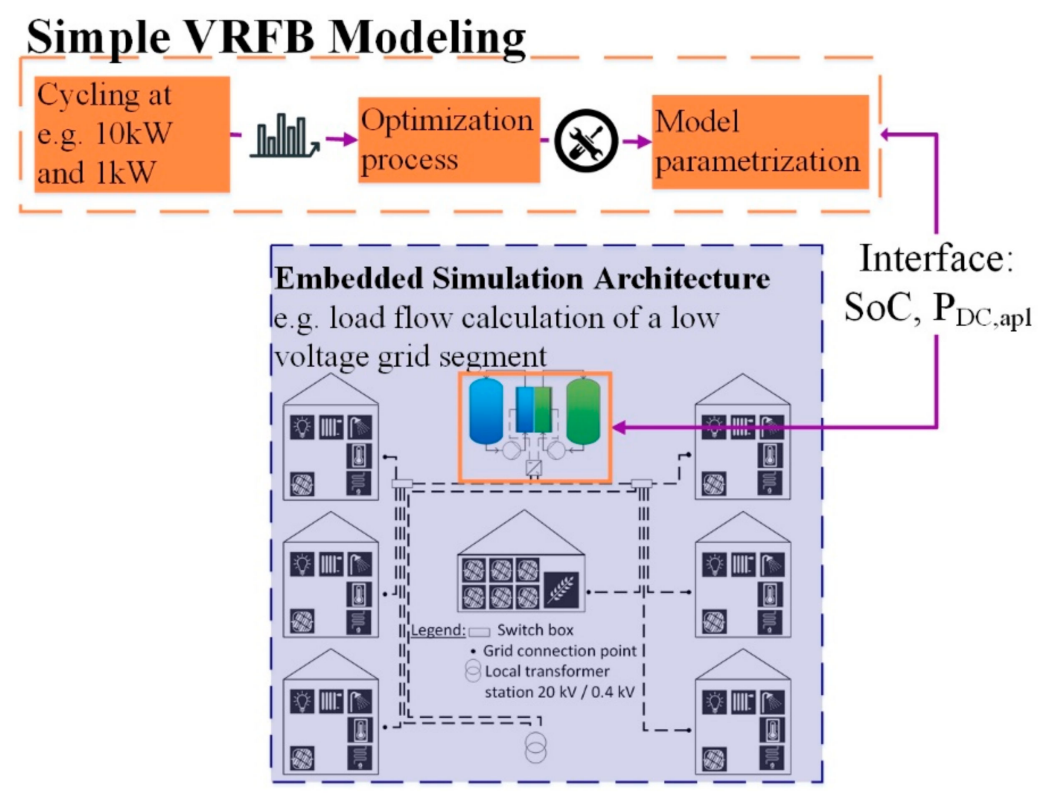

Figure 5. Schematic illustration of the complete simulation process (orange) and the interface to superimposed simulation architectures (blue).

\subsubsection{Physical Description of the Battery Model}

The following sections give a brief description of the differential-algebraic model used for the simulation model which can be divided in three parts. 


\section{Part I: Calculation of the SoC}

The theoretical SoC of a battery is defined as the available electric charge $Q(U)$ equals to the current $I(t)$ which is used to charge or discharge the battery integrated over the time [37]. Equation (1) shows the modified SoC calculation within the presented simulation model. While several published models calculate $\mathrm{SoC}$ change by multiplying stack power and time divided by energy capacity $[27,30,31]$ the proposed model calculates SoC changes by diving integral of currents used to charge or discharge the battery in this time step by real storage capacity. While, $I(t)$ indicates the current used to charge or discharge the battery, $I_{\text {Loss }}$ represents the current losses due to the internal processes in the VRFB like shunt currents or vanadium permeation. The variable $C_{\text {Stor }}$ with physical unit $\mathrm{Ah}$ represents the real storage capacity of the battery system normally unequals the theoretical storage capacity $C_{\text {Theo }}$ :

$$
\frac{\mathrm{dSOC}(t)}{\mathrm{d} t}=-\frac{I(t)+I_{\text {Loss }}}{C_{\text {Stor }}}
$$

As stated by König, $C_{\text {Stor }}$ is dependent on the mixture of Vanadium ions in the electrolyte tanks, normally not accessible during operation mode [38]. Comparable VRFB models $[27,30,31]$ calculate total energy capacity based on measurements, and some of them modified the equation in order to estimate not only theoretical, but also the real values for the energy capacity of the battery. Energy Engineers and System researchers often have no access to electrolyte analyzing techniques and even with some equipment $C_{\text {Stor }}$, usable during the battery operation cannot be determined exactly. Thus $C_{\text {Stor }}$ is chosen to be part of the parameter estimation process to ensure a simple and adjustable model in the proposed work.

\section{Part II: Calculation of the Cell Voltage}

The open circuit voltage (OCV) is the standard potential difference between two electrodes when no external source or load is connected and the battery is in equilibrium state [37]. Commonly, the Nernst equation is used to calculate the OCV of VRFB. While, the Nernst equation according to $[39,40]$ originally uses an activity factor for each species in the electrolyte, several modifications are published $[27,30,31,38,41]$ to simplify the Nernst equation for application-oriented modeling. The following literature based simplifications lead to Equation (2):

- Constant activity coefficients of both vanadium species and protons lead to a simplified logarithmic term with only reactant concentrations. The constants form together with the standard potential the formal cell potential $U_{0}^{\prime}$ [37-39].

- Proton concentration is assumed to be constant in both tanks and is also added to the formal cell potential $[38,40]$.

- $\quad$ Concentration of vanadium ions is related to the SoC of the battery $[27,30,31,38,41]$ :

$$
U_{0}=N_{\text {Cell }} U_{0}^{\prime}+\frac{N_{\text {Cell }} R T}{z F} \log \left[\frac{\text { SOC }^{2}}{(1-\mathrm{SOC})^{2}}\right]
$$

The voltage-current characteristics of a battery $U(I)$ are computed using the OCV $\left(U_{0}\right)$ calculated by the simplified Nernst equation from Equation (2) and the voltage drop caused by the internal ohmic resistance $R_{i}$ and the current $I(t)$ of the cell (Equation (3)) [37]. The combination of both modified Nernst and voltage-current equation lead the second part of the DC model (Equation (4)):

$$
\begin{gathered}
U(I)=N_{\text {Cell }} U_{0}-N_{\text {Cell }} I(t) R_{i} \\
U(I)=N_{\text {Cell }} U_{0}^{\prime}+\frac{N_{\text {Cell }} R T}{z F} \log \left[\frac{\mathrm{SOC}^{2}}{(1-\mathrm{SOC})^{2}}\right]-N_{\text {Cell }} I(t) R_{i}
\end{gathered}
$$


Equation (4) includes the following parameters: Faraday constant $F=96486 \mathrm{AsMol}^{-1}$, Gas constant $R=8.314 \mathrm{Jmol}^{-1} \mathrm{~K}^{-1}$, average ambient temperature $T$ and $z=1$ showing electrons transferred during the reactions also called valency of ion [42]. A defined number of cells $N_{\text {cell }}$ is used to determine the battery voltage. The SOC, the DC current $I(t)$, and the DC voltage $U(t)$ are variables calculated by the simulation model. $U_{0}^{\prime}$ is formal cell potential, which equals to $U_{0}$ if concentrations of all vanadium oxidation sates are equal. The ohmic resistance $R_{i}$, used to compare and evaluate material performance, depends on the components of the battery, e.g., bipolar plates, membrane, and the contact resistance in between. Again, both parameters $U_{0}^{\prime}$ and $R_{i}$, are material-based, often not accessible or separately measurable in closed battery systems. Cited by different research groups, internal resistances are often based on percentage literature values [30] or estimated by dividing voltage losses by stack current $[27,31]$. The estimation of the internal resistances is difficult without the knowledge of used materials inside the battery. Therefore, these two parameters were part of the estimation process in this study to provide a simple and adjustable model.

\section{Part III: Calculation of Power}

Equation (5) shows the typical power balance of a battery. The applied DC power $P(t)_{a p l}$ is used for cycling the battery with current $I(t)$ causing an applied DC voltage $U(I)$ and overall system losses $P_{\text {loss }}$. As the system is controlled using fixed power values, $P(t)_{\text {applied }}$ is the control parameter of the battery system and also the external input parameter of the simulation model. The parameter $P_{\text {loss }}$ covers the internal DC system losses of the battery excluding losses linked to pumps, inverters, battery management system, and cooling system of the battery, while $I_{\text {Loss }}$ reflects the self-discharge current or leakage current inside the battery stack. Simulation models using sub-modeling steps for the auxiliary hardware like pumps display the related losses separately. The DC battery model in this study is designed without sub-systems, and $I_{\text {Loss }}$ is a part of the optimization process to ensure a simple and adjustable model:

$$
P(t)_{D C, a p l}=U(I) I(t)-P_{\text {loss }}
$$

To conclude, the model is based on one differential Equation (1) and two algebraic Equations (4) and (5). State variables are SOC, $U(I), I(t), P(t)_{\text {apl }}$ while the battery specific parameters $I_{\text {Loss }}, C_{\text {Stor }}, U_{0}^{\prime}$ and $R_{i}$ are optimized during the optimization routine. Initial conditions for differential Equation (1) are $\mathrm{SoC}=80 \%$ to start discharging and $\mathrm{SoC}=20 \%$ to start charging.

\subsubsection{Boundary Conditions of Optimization Process and State Variable Definition}

As discussed above the VRFB model is based on one differential equation and two algebraic equations which are solved for different charging and discharging powers $P_{a p l}$. Beyond $P_{\text {apl }}$ and before the model is useable, four fitting parameters $\left(C_{\text {Stor }}, I_{\text {Loss }}, U_{0}^{\prime}\right.$ and $R_{i}$ ) are selected during a optimization process also called parametrization. Aiming at high modelling accuracy, an optimization function is applied for different input data scopes, and optimal values of fitting parameters are defined. Once the model is parametrized, a universal usage in integrated energy system simulations without any further parametrization is possible. The parametrization itself is performed with two different scopes, the power specific and the universally valid. While, universally valid (UVP) means that the selected fitting parameters can be used at any power stage, power specific parametrization (PSP) generates a lookup table with fitting parameters for different power steps.

Figure 6 illustrates the optimization process consisting of three nested loops (index $p$, index $s$, index $k$ ) executed one after the other. The vector $P_{a p l}$ contains all performed measurements (compare Section 3.1, $P_{a p l}=[1 \mathrm{~kW}, 2.5 \mathrm{~kW}, 5 \mathrm{~kW}, 7.5 \mathrm{~kW}, 10 \mathrm{~kW}]$ ). Prior to the start of the optimization routine, $\mathrm{p}$ is selected as an index in $P_{a p l}$ to choose the input data scope. While varying index $p$ the optimization reveals the simulation accuracy for different input data scopes. For example, using only the $1 \mathrm{~kW}$ charging/discharging cycle 
for the parametrization, index $p=1$ need to be chosen. Moreover, single cycles, as well as different combinations of cycles are pre-defined within the list of cases Table 1 in Section 2. If $p=[1 ; 2]$ the $1 \mathrm{~kW}$ and $2.5 \mathrm{~kW}$ cycle are both used for the optimization process.

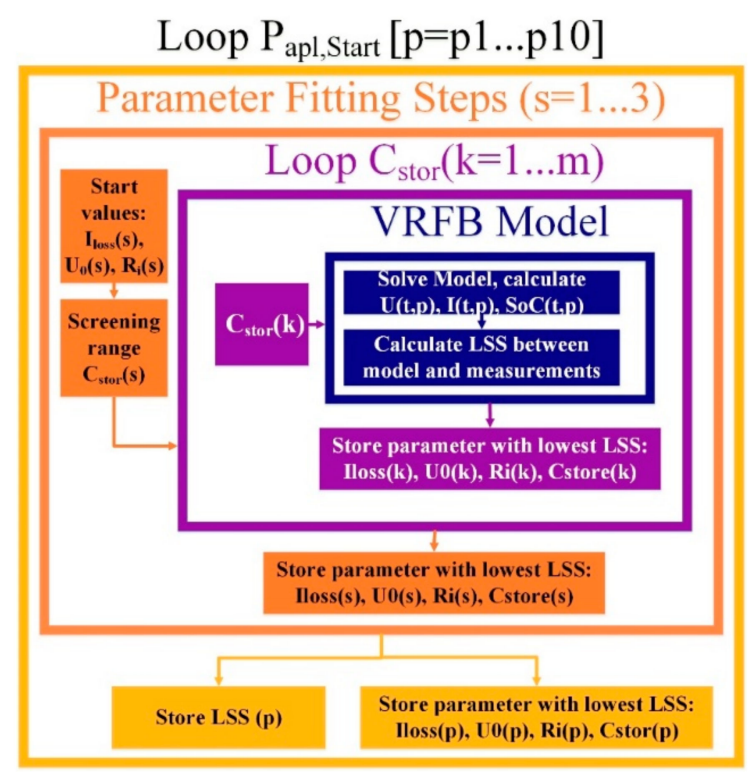

Figure 6. Schematic illustration of the steps performed during the fitting process (index $p$ is used as an index in vector $P_{a p l}=[1,2.5,5,7.5,10]$ in $\mathrm{kW}$ for varying the input data scope, index $s$ is used for the optimization steps $(s=1-3)$ and index $k$ is used for the step size in the screening range of $C_{\text {Stor }}$.

After the start vector $P_{a p l}$ is chosen, three fitting steps with index $s(s=1-3)$ are performed. During every step $s$ the same routine (Figure 6, violet and blue colored loops) is performed with the objective to estimate the four fitting parameters of the model while minimizing the deviation error between measurements and VRFB model. Starting from $s=1$, different starting values for the fitting parameters are selected for the optimization. In the pre-optimization step $(s=1)$, first guesses for fitting parameters $I_{\text {Loss }}, U_{0}{ }^{\prime}$, and $R_{i}$ as well as a range for the screening of $C_{\text {Stor }}$ are defined. Therefore, the fitting parameters are index with SV e.g., $C_{\text {Stor,Sv }}$ meaning start value. In an iterative loop the best fitting values during one step $s$ are used as start values for the next step. Therefore, the algorithm approaches an optimal solution for the selected index $p$ after the final step $s=3$. While, fitting parameters $I_{\text {Loss, }}, U_{0}{ }^{\prime}$, and $R_{i}$ always have fixed values during one step $s$ (Figure 6 , orange colored loop), $C_{\text {Stor }}$ is varied in a defined ranges listed in Table 6 . The variable stepsize defines the amount of values in vector $C_{\text {Stor }}(k)$ and is used to calculate the stepvalue in accordance with Equation (6).

$$
\text { stepvalue }=\frac{\left(1+k_{\mathrm{Cstor}}\right) \times C_{\mathrm{Stor}, \mathrm{SV}}-\left(1-k_{\mathrm{Cstor}}\right) \times C_{\mathrm{Stor}, \mathrm{SV}}}{(\text { stepsize }-1) \times C_{\mathrm{Stor}, \mathrm{SV}}}
$$

Table 6. Formulation of screening ranges of $C_{\text {Stor }}$.

\begin{tabular}{cc}
\hline Optimization Step & $\begin{array}{c}\text { Screening Range of } C_{\text {Stor }} \\
\text { (Startvalue Calculated with Equation (6)) }\end{array}$ \\
\hline$s=1$ & $\left(1-k_{\text {Cstor }}\right) \times C_{\text {Stor,SV }} \leq C_{\text {Stor }}(k)+$ stepvalue $\leq\left(1+k_{\text {Cstor }}\right) \times C_{\text {Stor,SV }}{ }^{1}$ \\
$s=2$ & $\left(1-k_{\text {Cstor }}\right) \times C_{\text {Stor,SV }} \leq C_{\text {Stor }}(k)+$ stepvalue $\leq\left(1+k_{\text {Cstor }}\right) \times C_{\text {Stor,SV }}{ }^{2}$ \\
$s=3$ & $\left(1-k_{\text {Cstor }}\right) \times C_{\text {Stor,SV }} \leq C_{\text {Stor }}(k)+$ stepvalue $\leq\left(1+k_{\text {Cstor }}\right) \times C_{\text {Stor,SV }}$ \\
\hline${ }^{1} k_{\text {Cstor }}=0.05$, stepsize $=30 .{ }^{2} k_{\text {Cstor }}=0.015$, stepsize $=60$.
\end{tabular}

As discussed above, the state parameters are assessed with different values before the optimization function is applied to the VRFB model. The indexes $p, s$ and $k$ define the 
amount of iterations performed within the optimization process. To sum up, the following state parameters need to be set:

- Define index $p$ in vector $P_{a p l}$ to iterate different input data scopes.

- Define start values for $C_{\mathrm{Stor}, \mathrm{SV}}, I_{\mathrm{Loss}, \mathrm{SV}}, U_{0}{ }^{\prime} \mathrm{SV}$, and $R_{i, \mathrm{SV}}$ and adjust them after every step $s=1, \ldots, 3$.

- $\quad$ Calculate vector $C_{\text {Stor }}(k)$ for brute force screening for every step $s=1, \ldots, 3$.

\subsubsection{Optimization Function}

As discussed above, the optimization starts $(p=[p 1, \ldots, p 10] s=1, k=1)$ with supplying the VRFB model with predefined state parameters $\left(P_{a p l}\right.$, Start values of fitting parameters). The differential equations of the VRFB model (blue loop in Figure 6) are solved for all input data scopes of $P_{a p l}[p 1, \ldots, p 10]$. The optimization function calculates state variables $U_{\mathrm{Sim}}, I_{\mathrm{Sim}}$, and $\mathrm{SOC}_{\mathrm{Sim}}$ and compare them with measured values from Section 3.1 $U_{\text {Raw }}, I_{\text {Raw }}$, and $S O C_{\text {Raw }}$. A deviation error LSS is calculated by adopting the method of the least square sum between the model and the experiments based on Equation (7) [43]. The parameter $e_{i}$ in Equation (7) displays the deviation error between the experiments $\left(x_{i}, y_{i}\right)$ and the fitting curve $f\left(x_{i}\right)$ for each data point $i$. Aiming at minimizing the square sums the approach achieves the best fitting result [43]. As the optimization function reveals three state variable three, deviation errors $(E 1, E 2, E 3)$ are calculated for time steps q during all simulated cycles according to Equations (8)-(10):

$$
\begin{gathered}
\sum_{i=1}^{n} e_{i}^{2}=\sum_{i=1}^{n}\left[y_{i}-f\left(x_{i}\right)\right]^{2} \\
E_{1}=\sum_{1}^{q} e 1_{q}^{2}=\sum_{1}^{q}\left[U_{\text {Raw }, \mathrm{q}}-U_{\text {Sim }, \mathrm{q}}\right]^{2} \\
E_{2}=\sum_{1}^{q} e 2_{q}^{2}=\sum_{1}^{q}\left[I_{\text {Raw }, \mathrm{q}}-I_{\text {Sim }, \mathrm{q}}\right]^{2} \\
E_{3}=\sum_{1}^{q} e 3_{q}^{2}=\sum_{1}^{q}\left[\operatorname{SOC}_{\text {Raw }, \mathrm{q}}-\operatorname{SOC}_{\text {Sim }, \mathrm{q}}\right]^{2} \\
\operatorname{LSS}=E_{1}+E_{2}+E_{3} \\
\operatorname{WLSS}(p)=\left(\frac{\operatorname{LSS}(p)}{\left.\operatorname{minLSS}(p)_{p}-1\right) \times 100 \%}\right.
\end{gathered}
$$

Equation (11) sums up the last square sums to reveal the deviation between the model and the experiments LSS during the optimization step. It needs to be highlighted that LSS has no physical unit as it is a globally summed deviation error for all state variable and performed cycles. To increase comparability, the weighted LSS (WLSS) based on Equation (12) is used. For every index $p$ the LSS is divided by the lowest LSS during the parametrization $(p 1, \ldots, p 10)$. By comparing all $\operatorname{WLSS}(p)$, not only the deviation error itself, but also the increase of the deviation error while reducing the input data scope is found.

The Matlab optimization function "FMINCON" is applied to reveal optimal fitting parameters corresponding to the minimal LSS for iterations in $k$ during step $s$. After all iterations with $k$ and $s$, optimal fitting parameters with lowest LSS are stored for every index $p$. By comparing the results for different indexes $p$ the impact of the data scope on the simulation accuracy is revealed.

\section{Conclusions}

In a two-step process, this study shows the parametrization, optimization, and validation of a DC grey box VRFB model using measurements from a $10 \mathrm{~kW} / 100 \mathrm{kWh}$ VRFB. Based on mathematical equations, an optimization process is developed to adjust battery 
specific parameters while maximizing model accuracy. The specific battery parameters, also called fitting parameters, are real storage capacity, current losses, open circuit voltage and ohmic resistance. They were identified as parameters not easily accessed or measured within a closed battery system.

Charging and discharging cycles at $1 \mathrm{~kW}, 2.5 \mathrm{~kW}, 5 \mathrm{~kW}, 7.5 \mathrm{~kW}$, and $10 \mathrm{~kW}$ as well as different combinations of these values (evaluation cases) serve as input data for the optimization process. The evaluation cases involve different amounts of measurements and different measurement combinations based on full charging and discharging cycles ( 2 to 10 measurements). This allowed to investigate, which measurements or measurement combinations reflect the overall behavior of the battery in a meaningful way. Yielding reduced input data scopes, sufficient modelling accuracy should remain.

Comparing the evaluation cases and the resulting deviation error between the measurements and the simulation, the best results were found using all measurements $(1 \mathrm{~kW}$, $2.5 \mathrm{~kW}, 5 \mathrm{~kW}, 7.5 \mathrm{~kW}, 10 \mathrm{~kW}$ ). This case was defined as the initial point for investigating the effects of the data scope reduction on the accuracy of the simulation model. The weighted deviation error (WLSS) between experiments and model was used as an evaluation parameter.

Using more experimental data generally gives better results (Case 1), but the fitting accuracy is still sufficient for some cases of smaller data scope (Case 2A, Case 3A). Reducing the data scope from Case 1 (five charging and discharging cycles) to Case $3 \mathrm{~A}$ (three charging and discharging cycles) still leads to a small increase of WLSS of $2 \%$. Even further reduction of the input data scope to Case 2A (two charging and discharging cycles) shows a WLSS of $7 \%$. Using experimental cycling data with stable battery performance and high DC efficiency, model performance can be improved significantly. Comparing Case 3A and Case 3B, both including three charging and discharging cycles, it has been found that $1 \mathrm{~kW}$ cycle should be included into the parametrization process as it shows specific behavior with drops in the voltage and SoC profile. The same conclusion can be applied for Case 2A and Case 2B.

The first investigation indicates a sufficient battery model while reducing input data scope. This method was called universally valid parametrization as only one parameter set was used to simulate the complete battery performance. The presented model is able to obtain the temperature dependency of estimated parameters, but a limited set of experiments has not allowed it yet. Further experiments with the VRFB can be executed to study the temperature dependency more detailed. Moreover, model validation with different VRFB control experiments will be performed in a follow-up study.

The simulation model with the universal valid fitting parameters, found in this study, can be easily integrated into other simulation architectures to evaluate battery performance in different applications. The interface parameters for such evaluations are DC battery power and SoC of the battery, both calculated for every time step. A follow-up study further investigates the integration and performance of the VRFB model in energy system analysis and evaluates the performance of decentralized and centralized VRFB installations in the low-voltage grid. Moreover, the battery model will be used for further studies on the grid stability of low voltage grids with a high penetration of renewable energies.

Author Contributions: Conceptualization, C.Z., J.D., S.L., J.-R.H.-M., J.K. and K.-H.P.; methodology, C.Z., J.D.; software, J.D.; validation, C.Z. and J.D.; formal analysis, C.Z., J.D., S.L., J.-R.H.-M., J.K. and K.-H.P.; investigation, C.Z., J.D.; resources, C.Z.; data curation, C.Z., J.D., J.K. and K.-H.P.; writing-original draft preparation, C.Z.; writing-review and editing, C.Z., J.D., S.L., J.-R.H.-M., J.K. and K.-H.P.; visualization, C.Z.; Supervision, S.L., J.-R.H.-M., J.K. and K.-H.P.; project administration, C.Z., J.D., S.L., J.-R.H.-M., J.K. and K.-H.P.; funding acquisition, J.K. and K.-H.P. All authors have read and agreed to the published version of the manuscript.

Funding: This research was funded by INTERREG V, European Regional Development Fund of the European Union, grant number FSTORE/18. 
Data Availability Statement: The data presented in this study are available on request from the corresponding author. The data are not publicly available due to privacy.

Acknowledgments: The authors thank Felix Gackstatter from the Technology Centre Energy for performing the experiments as well as Saskia Dinter, Georg Heyer and Martin Frankenberger from the Technology Centre Energy for proofreading the article.

Conflicts of Interest: The authors declare no conflict of interest. The funders had no role in the design of the study; in the collection, analyses, or interpretation of data; in the writing of the manuscript, or in the decision to publish the results.

\section{References}

1. Aneke, M.; Wang, M. Energy storage technologies and real life applications-A state of the art review. Appl. Energy 2016, 179, 350-377. [CrossRef]

2. Maria, S.-K.; Miron, R.; Robert, R. All-Vanadium Redox Battery. U.S. Patent US4786567A, 11 February 1986.

3. Skyllas-Kazacos, M.; Kazacos, G.; Poon, G.; Verseema, H. Recent advances with UNSW vanadium-based redox flow batteries. Int. J. Energy Res. 2010, 34, 182-189. [CrossRef]

4. Skyllas-Kazacos, M.; Chakrabarti, M.H.; Hajimolana, S.A.; Mjalli, F.S.; Saleem, M. Progress in Flow Battery Research and Development. J. Electrochem. Soc. 2011, 158, R55-R79. [CrossRef]

5. Roznyatovskaya, N.; Noack, J.; Pinkwart, K.; Tübke, J. Aspects of electron transfer processes in vanadium redox-flow batteries. Curr. Opin. Electrochem. 2020, 19, 42-48. [CrossRef]

6. Charvát, J.; Mazúr, P.; Dundálek, J.; Pocedič, J.; Vrána, J.; Mrlík, J.; Kosek, J.; Dinter, S. Performance enhancement of vanadium redox flow battery by optimized electrode compression and operational conditions. J. Energy Storage 2020, 30, 101468. [CrossRef]

7. Messaggi, M.; Rabissi, C.; Gambaro, C.; Meda, L.; Casalegno, A.; Zago, M. Investigation of vanadium redox flow batteries performance through locally-resolved polarisation curves and impedance spectroscopy: Insight into the effects of electrolyte, flow field geometry and electrode thickness. J. Power Sources 2020, 449, 227588. [CrossRef]

8. Mazur, P.; Mrlik, J.; Pocedic, J.; Vrana, J.; Dundalek, J.; Kosek, J.; Bystron, T. Effect of graphite felt properties on the long-term durability of negative electrode in vanadium redox flow battery. J. Power Sources 2019, 414, 354-365. [CrossRef]

9. König, S.; Suriyah, M.R.; Leibfried, T. Innovative model-based flow rate optimization for vanadium redox flow batteries. J. Power Sources 2016, 333, 134-144. [CrossRef]

10. Lucas, A.; Chondrogiannis, S. Smart grid energy storage controller for frequency regulation and peak shaving, using a vanadium redox flow battery. Int. J. Electr. Power Energy Syst. 2016, 80, 26-36. [CrossRef]

11. Müller, M.; Viernstein, L.; Truong, C.N.; Eiting, A.; Hesse, H.C.; Witzmann, R.; Jossen, A. Evaluation of grid-level adaptability for stationary battery energy storage system applications in Europe. J. Energy Storage 2017, 9, 1-11. [CrossRef]

12. Li, Y.; Zhang, X.; Bao, J.; Skyllas-Kazacos, M. Control of electrolyte flow rate for the vanadium redox flow battery by gain scheduling. J. Energy Storage 2017, 14, 125-133. [CrossRef]

13. Yang, W.W.; Yan, F.Y.; Qu, Z.G.; He, Y.L. Effect of various strategies of soc-dependent operating current on performance of a vanadium redox flow battery. Electrochim. Acta 2018, 259, 772-782. [CrossRef]

14. Guarnieri, M.; Trovò, A.; Picano, F. Enhancing the efficiency of kW-class vanadium redox flow batteries by flow factor modulation: An experimental method. Appl. Energy 2020, 262, 114532. [CrossRef]

15. Pugach, M.; Parsegov, S.; Gryazina, E.; Bischi, A. Output feedback control of electrolyte flow rate for Vanadium Redox Flow Batteries. J. Power Sources 2020, 455, 227916. [CrossRef]

16. Viswanathan, V.; Crawford, A.; Stephenson, D.; Kim, S.; Wang, W.; Li, B.; Coffey, G.; Thomsen, E.; Graff, G.; Balducci, P.; et al. Cost and performance model for redox flow batteries. J. Power Sources 2014, 247, 1040-1051. [CrossRef]

17. Minke, C.; Kunz, U.; Turek, T. Techno-economic assessment of novel vanadium redox flow batteries with large-area cells. J. Power Sources 2017, 361, 105-114. [CrossRef]

18. Rodby, K.E.; Carney, T.J.; Ashraf Gandomi, Y.; Barton, J.L.; Darling, R.M.; Brushett, F.R. Assessing the levelized cost of vanadium redox flow batteries with capacity fade and rebalancing. J. Power Sources 2020, 460, 227958. [CrossRef]

19. Li, M.-J.; Zhao, W.; Chen, X.; Tao, W.-Q. Economic analysis of a new class of vanadium redox-flow battery for medium- and large-scale energy storage in commercial applications with renewable energy. Appl. Therm. Eng. 2017, 114, 802-814. [CrossRef]

20. Parasuraman, A.; Lim, T.M.; Menictas, C.; Skyllas-Kazacos, M. Review of material research and development for vanadium redox flow battery applications. Electrochim. Acta 2013, 101, 27-40. [CrossRef]

21. Weber, A.Z.; Mench, M.M.; Meyers, J.P.; Ross, P.N.; Gostick, J.T.; Liu, Q. Redox flow batteries: A review. J. Appl. Electrochem. 2011, 41, 1137-1164. [CrossRef]

22. Sarkar, T.; Bhattacharjee, A.; Samanta, H.; Bhattacharya, K.; Saha, H. Optimal design and implementation of solar PV-windbiogas-VRFB storage integrated smart hybrid microgrid for ensuring zero loss of power supply probability. Energy Convers. Manag. 2019, 191, 102-118. [CrossRef]

23. Gonçalves, J.; Martins, A.; Neves, L. Methodology for real impact assessment of the best location of distributed electric energy storage. Sustain. Cities Soc. 2016, 26, 531-542. [CrossRef] 
24. Ippolito, M.G.; Di Silvestre, M.L.; Sanseverino, E.R.; Zizzo, G.; Graditi, G. Multi-objective optimized management of electrical energy storage systems in an islanded network with renewable energy sources under different design scenarios. Energy 2014, 64, 648-662. [CrossRef]

25. Duun-Henriksen, A.K.; Schmidt, S.; Røge, R.M.; Møller, J.B.; Nørgaard, K.; Jørgensen, J.B.; Madsen, H. Model identification using stochastic differential equation grey-box models in diabetes. J. Diabetes Sci. Technol. 2013, 7, 431-440. [CrossRef]

26. Baccino, F.; Marinelli, M.; Nørgård, P.; Silvestro, F. Experimental testing procedures and dynamic model validation for vanadium redox flow battery storage system. J. Power Sources 2014, 254, 277-286. [CrossRef]

27. DAgostino, R.; Baumann, L.; Damiano, A.; Boggasch, E. A Vanadium-Redox-Flow-Battery Model for Evaluation of Distributed Storage Implementation in Residential Energy Systems. IEEE Trans. Energy Convers. 2015, 30, 421-430. [CrossRef]

28. Bhattacharjee, A.; Saha, H. Design and experimental validation of a generalised electrical equivalent model of Vanadium Redox Flow Battery for interfacing with renewable energy sources. J. Energy Storage 2017, 13, 220-232. [CrossRef]

29. Turker, B.; Klein, S.A.; Hammer, E.-M.; Lenz, B.; Komsiyska, L. Modeling a vanadium redox flow battery system for large scale applications. Energy Convers. Manag. 2013, 66, 26-32. [CrossRef]

30. Chahwan, J.; Abbey, C.; Joos, G. VRB Modelling for the Study of Output Terminal Voltages, Internal Losses and Performance. In Proceedings of the IEEE Canada Electrical Power Conference, Montreal, QC, Canada, 25-26 October 2007; pp. 387-392. [CrossRef]

31. Qiu, X.; Nguyen, T.A.; Guggenberger, J.D.; Crow, M.L.; Elmore, A.C. A Field Validated Model of a Vanadium Redox Flow Battery for Microgrids. IEEE Trans. Smart Grid 2014, 5, 1592-1601. [CrossRef]

32. Skyllas-Kazacos, M.; Kazacos, M. State of charge monitoring methods for vanadium redox flow battery control. J. Power Sources 2011, 196, 8822-8827. [CrossRef]

33. Ontiveros, L.J.; Mercado, P.E. Modeling of a Vanadium Redox Flow Battery for power system dynamic studies. Int. J. Hydrogen Energy 2014, 39, 8720-8727. [CrossRef]

34. Cellstrom GmbH. Vanadium Redox Durchfluss Batterie-FB 10-100; Betriebsanleitung, Cellstrom GmbH: Wiener Neudorf, Austria, 2012.

35. Schreiber, M.; Harrer, M.; Whitehead, A.; Bucsich, H.; Dragschitz, M.; Seifert, E.; Tymciw, P. Practical and commercial issues in the design and manufacture of vanadium flow batteries. J. Power Sources 2012, 206, 483-489. [CrossRef]

36. Trovò, A.; Picano, F.; Guarnieri, M. Comparison of energy losses in a $9 \mathrm{~kW}$ vanadium redox flow battery. J. Power Sources 2019, 440, 227144. [CrossRef]

37. Kurzweil, P.; Dietlmeier, O. Elektrochemische Speicher. In Superkondensatoren, Batterien, Elektrolyse-Wasserstoff, Rechtliche Grundlagen; Springer: Wiesbaden, Germany, 2015; ISBN 978-3-658-10899-1.

38. König, S. Model-Based Design and Optimization of Vanadium Redox Flow Batteries. Ph.D. Thesis, Karlsruher Instituts für Technologie, Karlsruhe, Germany, 2017.

39. Hudak, N.S. Practical thermodynamic quantities for aqueous vanadium- and iron-based flow batteries. J. Power Sources 2014, 269, 962-974. [CrossRef]

40. Corcuera, S.; Skyllas-Kazacos, M. State-of-Charge Monitoring and Electrolyte Rebalancing Methods for the Vanadium Redox Flow Battery. Eur. Chem. Bull. 2012, 1, 511-519. [CrossRef]

41. Fathima, A.H.; Palanismay, K. Modeling and Operation of a Vanadium Redox Flow Battery for PV Applications. Energy Procedia 2017, 117, 607-614. [CrossRef]

42. Kjelstrup, S.; Bedeaux, D. Non-Equilibrium Thermodynamics of Heterogeneous Systems; World Scientific: Hackensack, NJ, USA, 2008; ISBN 978-981-277-913-7.

43. Molugaram, K.; Rao, G.S. Statistical Techniques for Transportation Engineering; Butterworth-Heinemann: Oxford, UK, 2017; ISBN 978-0-12-811555-8. 